\title{
Audio-Visual Materials in an Integrated Literacy-Mechanical Skills Training Program for Young Unemployed Adults
}

\section{Orest Cap \\ Odarka S. Trosky \\ Barbara Wynes \\ Robin Cutts}

\begin{abstract}
This article describes how audio-visual materials were selected and used for a group of thirty unemployed young adults, ranging in ages (17-21), attending an integrated literacy-mechanical skills program. This program consisted of an initial two months of class activities followed by approximately seven months in the field and a final two weeks in class. The audio-visual materials which met Vander Meer's (1973) criteria of appropriateness, to reflect the curriculum and to elicit expected and desired behavior in the learner, were selected on the basis of the Von Mondfrans and Houser six step paradigm (1973) to relate to performance-based objectives. The selected materials did not necessarily reflect the very best nor the most recent in the field, rather they represented the best and most recent from those readily available. Evaluation through questionnaires, reports, observations and participant comments indicated that the audio-visual materials used in the program closely related to the three main functions of audio-visual materials in vocational instruction.
\end{abstract}

In his essay The Impact of New Materials and Media on Curriculum Design, Vander Meer (1973) argued that the use of educational media must achieve a wider set of goals and that "the degree of goal achievement is directly proportional to the appropriateness and the variety of media available to the teacher and the learner " (p. 104). Vander Meer defined appropriateness as the ability to reflect the curriculum and to elicit expected and desirable behavior in the learner.

This article will describe how certain audio-visual materials were selected and used for a group of unemployed young adults attending an integrated literacy-mechanical skills pilot program at the Faculty of Education, University of Manitoba, and which met the criteria of appropriateness as defined by Vander Meer (1973).

Funded by Employment and Immigration Canada, the Youth Training Option Program (Y.T.O.) was a 10-month program with two broad goals:

Orest Cap is an Associate Professor of Vocational-Technical Education and Odarka S. Trosky is a Professor, with teaching and research interests in reading-writing interrelationships. Barbara Wynes and Robin Cutts are graduate students and Program Coordinators. All are with the University of Manitoba, Winnipeg, Manitoba. Preparation of this manuscript was funded by Employment and Immigration Canada. 
(1) intensive training in the communication skills of listening, speaking, reading and writing as they relate to job application techniques and on-the-job activities; and

(2) intensive field training in automotive mechanical skills.

The training consisted of an initial two months of class activities followed by approximately seven months in the field (80\% of the time in the field and $20 \%$ in class) and a final two weeks in class to write various examinations.

The Y.T.P. trainees were 30 unemployed men and women ranging in ages 17-21, who had an interest in automotive mechanics. Their academic background ranged from partial completion of a secondary program to high school graduates. These trainees had been selected from those who responded to advertisements in local newspapers and unemployment agencies. As the program began, certain major characteristics of these trainees emerged: they were non-risk takers in coursework, comfortable only with short-term goals, and they were concrete-oriented with short attention spans. The reading abilities ranged from Grade 6 to college according to the Advanced 1 Metropolitan Achievement Test, Form JS, with a median of grade 9 . Consequently the learning activities had to be concrete in the content with many audio-visual units, very practical, and structured into short, snappy presentations with clearly stated objectives.

\section{MATCHING AUDIO-VISUAL MATERIALS TO THE OBJECTIVES AND TRAINEES}

The visual aids were selected on the basis of the Van Mondfrans and Houser paradigm (1973) which has six steps: identifying objectives; identifying available media with their stimulus characteristics; identifying learners' cognitive ability, perceptual and personality characteristics and relevant past experience; matching objectives with the media; organizing a match between the media and learners' characteristics; presenting the media; and evaluating learner's achievements.

The objectives as spelled out by the Employment and Immigration Canada fall into four areas: job application strategies, interpersonal skills including leaming and communication abilities, technology in the workplace, and on-the-job skills which explored attitudes, ethical behaviour, introductory aspects related to auto mechanics and safety. With these objectives in mind, a search of audio-visual materials was undertaken.

The selected materials did not necessarily reflect the very best nor the most recent in the field, rather they represented the best and most recent from those readily available in the province of Manitoba in relation to the program's general objectives. Thus, from a list of films, video tapes and video discs at the Manitoba Department of Education, the University of Manitoba, and the Ford Motor Company (see appendix), the following were selected and presented in the order listed below in relation to seven specified performance-based objectives:

I. Objective: Having viewed visual materials related to job application, the trainee will identify key points in the entire process of applying for a job. 


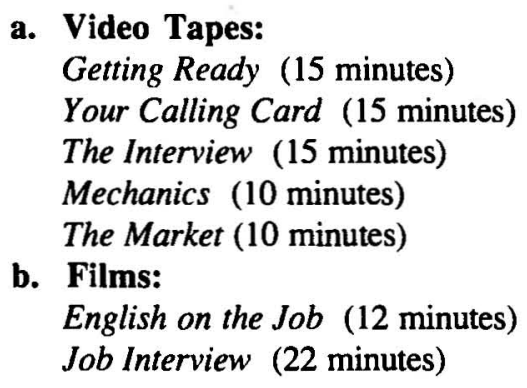

Since the trainees revealed hesitation in role-playing, these films became excellent vehicles through which realistic dialogue was scripted and undertaken without fear of risk. Gradually the trainees relaxed and began to go through the job application activities with some confidence. The visual materials also were beneficial in building positive interrelationships among the trainees since they began to function as a group or team. The objective was achieved in the trainees' abilities to fill out application forms, answer newspaper advertisements, and successfully role play in a job interview situation.

II. Objective: To develop awareness of risk-taking as an integral part of adjusting to change, the trainee will discuss salient features of such adjustments depicted in specific films.

Films:

Future Shock (42 minutes)

Focus on Change: The Third Wave (90 minutes)

Each of these films was first shown in its entirety for a context, and then each was shown in segments to facilitate recognition and discussion of certain aspects regarding future change and how an individual can productively adjust. In the discussions the trainees experienced concerns about the future, how best one can deal with unforeseen circumstances, and how to relate to others as situations unfold.

III. Objective: After viewing two films, the trainee will practice skills of effective communication and specific approaches to improving interpersonal understanding.

Films:

The Power of Listening (26 minutes)

Person to Person Communication (14 minutes)

Because the trainees were still hesitant to role play, these films were effective in breaking down many of the barriers to those interpersonal relationships essential in the work place. The practice sessions increased confidence, eased tensions and facilitated attention to the actual communication skills under practice. The observers of the role playing activities had tangible aspects upon which to comment, and upon which concrete suggestions could be offered. In this way, the films helped the trainees' preparedness for their field 
work which was launched immediately after working with these films.

IV. Objective: To develop an awareness that individual actions and speech are a reflection of one's background such as knowledge, experience, and cultures, the trainee will view a set of video tapes and then cite specific actions and speeches from his/her own field experiences which should or could facilitate effective interpersonal understanding and communication.

\section{Video Tape:}

What You Are Is Where You Were When (total 89 minutes)

By illustrating how each generation's attitudes, behaviours and reactions to change differ due to background, the videotapes provide an excellent basis for discussions and activities in the unit on communication, including the need for empathy and understanding in interpersonal relationships. As the trainees were now in the field for $80 \%$ of their training, these videos proved to be extremely effective in promoting good working relationships in the field extending to the personnel on the host sites and the supervising staff.

V. Objective: After some field experience and viewing related visual materials, the trainee will demonstrate specific mechanical knowledge in a set of written assignments.

a. Films:

$K$-Cycle Engine (18 minutes)

Gasoline Engine (8 minutes)

Electronic Fuel Systems

New Automotive Development

b. Laser Discs:

1982 Video Disc - 1982 New Model Service Features

1984 Video Disc - Gas Engine Fuel Injection

1985 Video Disc - Electronic Fuel Injection

The films were effective in illustrating some of the aspects of knowledge the trainees were acquiring in the field. The discussions that followed viewing of each of these materials demonstrated that more of this type of audio-visual materials would be useful in similar training programs.

VI. Objective: The trainee will discuss the role of computers in the mechanical world as depicted in specific films.

Films:

Now the Chips are Down (50 minutes)

The Silicon Factor: What's It All About (40 minutes)

Sink or Swin (40 minutes)

And What of the Future? (40 minutes) 


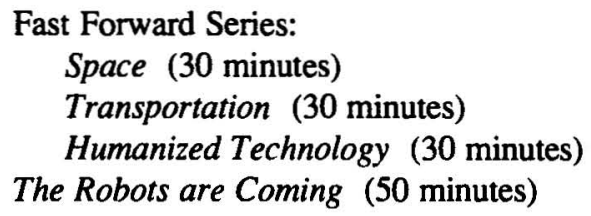

Since these films were used as integral portions in a unit in the curriculum on practical applications of the computer, the students were expected to appreciate the importance of new technology entering the workplace. However, some of the information was a bit too technical and unrealistic in terms of the current job demands, thus the instructional staff had to adjust their instructional program accordingly. Once this was done, the follow-up exercises were successfully completed, leaving the trainees with a better understanding of how the computer works and how it can help them individually, both at the workplace and personally.

VII. Objective: The trainee will specify personal safety practices in the workplace as depicted in a particular film and describe how these practices are being modified according to conditions in the workplace.

Film:

On Your Back (31 minutes)

This film was studied as the trainees were progressing through their field experiences and the safety unit in their program of studies. This particular film was extremely effective in that it elicited much discussion with specific examples from the individual workplaces in illustration. The awareness of being safety conscious at all times was evident at the workplace according to supervising staff and the personnel at the host sites.

\section{EVALUATION OF TRAINEES' ACHIEVEMENT}

From a review of the literature related to the role of audio-visual materials in vocational instruction (Brewer, 1982; Goldstein, 1980; Heidt, 1978) it would appear that there are at least three main functions:

(a) contribute to trainees' motivation by spreading the desire to be an active and contributing member of society;

(b) provide each trainee with information and skill development relevant to the world of work; and

(c) contribute to the individual's continuing education.

In determining the degree to which these three functions were met, several procedures were undertaken: an individual questionnaire was completed by the trainees; reports of the field supervisors' observations of each trainee in the workplace; trainee's oral comments about the visual material in the program; and comments about the trainee by personnel at 
the host site. A synthesis of these sources of information supported the class observations of the instructional staff: that the visual materials achieved the goal of providing information and skill development as related to the world of work; that the materials influenced the trainees' awareness of continuing education to the degree that several trainees were planning to return to formal education; and the materials assisted them in attaining gainful employment.

In summary, it would appear that the visual materials identified in this article are useful in an integrated literacy-mechanical skills program for young unemployed adults in that they are consistent with Vander Meer's definition of appropriateness (1973): the materials reflected the curriculum and elicited expected and desirable behaviour in the learner.

\section{REFERENCES}

Brew, N. B. (1982). Tailoring vocational education to adult needs. In C. Kleving (Ed.), Materials and methods in adult and continuing education. Los Angeles: Klevens Publications, Inc.

Goldstein, H. (1980). Training and education in industry. Washington, DC: National Institute for Work and Learning.

Heidt, E. V. (1978). Instructional media and the individual learner. New York: Nichols Publishing.

Vander Meer, A. W. (1973). The impact of new materials and media on curricular design. Audio-Visual Technology and Learning, 6, 100-104.

Van Mondfrans, A. P., \& Houser, R. L. (1973). Selecting media to present basic concepts. Audio-Visual Technology and Learning, 6, 81-84. 